\title{
BOTTOM TO TOP APPROACH FOR RAILWAY KPI GENERATION
}

\author{
Roberto VILLAREJO ${ }^{1}$, Carl-Anders JOHANSSON ${ }^{1}$, Urko LETURIONDO ${ }^{1,2}$, \\ Victor SIMON ${ }^{1}$, Dammika SENEVIRATNE ${ }^{1}$, Diego GALAR ${ }^{1}$ \\ Luleå University of Technology ${ }^{1}$ \\ IK4-Ikerlan, Arrasate-Mondragón ${ }^{2}$
}

\begin{abstract}
:
Railway maintenance especially on infrastructure produces a vast amount of data. However, having data is not synonymous with having information; rather, data must be processed to extract information. In railway maintenance, the development of key performance indicators (KPIs) linked to punctuality or capacity can help planned and scheduled maintenance, thus aligning the maintenance department with corporate objectives. There is a need for an improved method to analyse railway data to find the relevant KPIs. The system should support maintainers, answering such questions as what maintenance should be done, where and when. The system should equip the user with the knowledge of the infrastructure's condition and configuration, and the traffic situation so maintenance resources can be targeted to only those areas needing work. The amount of information is vast, so it must be hierarchized and aggregated; users must filter out the useless indicators. Data are fused by compiling several individual indicators into a single index; the resulting composite indicators measure multidimensional concepts which cannot be captured by a single index. The paper describes a method of monitoring a complex entity. In this scenario, a plurality of use indices and weighting values are used to create a composite and aggregated use index from a combination of lower level use indices and weighting values. The resulting composite and aggregated indicators can be a decision-making tool for asset managers at different hierarchical levels.
\end{abstract}

Key words: railway assets, fusion, hierarchy, aggregation, KPI, performance, condition monitoring, CMMS

\section{INTRODUCTION}

The railway industry seeks maximum track availability at the lowest possible cost. Therefore, a proper asset management policy is essential. Such a policy requires that asset managers receive accurate information. This can be facilitated by the use of indicators, a popular decision-making support tool in asset management, especially in maintenance [1]. However, the recent flurry of indicator related activity has led some to argue there is a danger of information overload. Simply stated, asset managers need indices that give proper information to the right people. Yet even in the recently published standard [2] on maintenance performance indicators where $71 \mathrm{KPIs}$ are proposed, the potential users of these indices are not identified.

The problem of having a large number of indicators comes also from the fact that data acquisition has become relatively simple and cheap with the introduction of modern and powerful hardware systems and software. Thus, the enormous amount of data, i.e. data overload, is a problem in itself. When collection is simple and inexpensive, many data can be gathered, but sophisticated data mining algorithms may be required to get useful information. When the data are more difficult to collect, an organisation needs to decide if their value to the company, usually to a single hierarchical level, is worth the effort and cost. This is accomplished by establishing what is important at different levels, i.e., determining the objectives at each organisational level and ensuring they emanate from the corporate ones. Once user needs are fully understood, it will be possible to determine the maintenance strategy and its required resources and systems.

Asset managers are a disparate group making decisions about operation and maintenance, and they have specific requirements of indicators $[1,3]$. Their duties span different disciplines of asset exploitation at different hierarchical levels. In the context of global business competition, decision-makers are interested in the relationship between asset management and company profitability. Indicators should, therefore, concentrate on the interaction, rather than on asset management alone.

In summary, there are two main points that need to be considered when selecting and using indicators. First, only a limited number of indicators should be used to convey the performance of assets due to the fact that too many indicators can compromise the legibility of the information. Second, the information should be presented in a format tailored to decision-making. This last requirement implies the construction of indicators that reduce the number of parameters needed to give precise account of a situation.

\section{THE NEED TO MEASURE MAINTENANCE PERFORMANCE}

Today's railways face increasing pressure from customers and owners to improve safety, capacity, quality and reliability of the rail system while controlling expenses and tightening budget [4]. That is why, with fewer resources and shrinking budgets, having a proper maintenance man- 
agement system in place to assist managers and engineers to get the most out of their existing infrastructure assets is essential. In this regard, the maintenance of largeinvestment equipment, once thought to be a necessary evil, is now considered key to improving cost effectiveness and creating additional value by delivering better and more innovative services to the customers. Moreover, it is now considered as a mode of gaining profit through the operations.

With the change in the strategic thinking of organisations, it is crucial to measure, control and improve asset maintenance [5]. The main challenge is choosing efficient and effective strategies so organisations can enhance and continually improve their operational capabilities and reduce their maintenance costs. Therefore, in addition to formulating maintenance policies and strategies for asset maintenance, it is equally important to measure their performance.

Maintenance performance measurement (MPM) is defined as "the multidisciplinary process of measuring and justifying the value created by maintenance investment, and taking care of the organisation's stockholder's requirements viewed strategically from the overall business perspective" [6]. It is considered an important element for understanding the value created by maintenance, reevaluating and revising maintenance policies and techniques, justifying investments in new trends and techniques in maintenance services, revising resource allocations, understanding the effect of maintenance on other functions and stakeholders as well as on health and safety [7].

Unfortunately, these maintenance metrics have often been misinterpreted and many companies apply them incorrectly. The metrics should not be used to show workers they are not doing their jobs. They should not be used to satisfy the company's ego, i.e. to show the company is working excellently. Performance measurements, when used properly, should highlight opportunities for improvements, modifications, detect problems and, ultimately, help to find solutions [8]. The work of Mata and Aller [9] provides an overview of the state of maintenance, its current problems and the need for adequate metrics to quantify it. The historical view of maintenance, mixed with traditional issues of performance measurement, creates problems developing and implementing a comprehensive package for measuring maintenance management performance [10]. For example, human factors affect the selection of the metric and its application, along with the subsequent use of the produced measurement. There is also a need to delineate responsibilities.

\section{SCORECARDS AND AGGREGATION OF PERFORMANCE IN- DICATORS}

It is essential to find the right indicators for the different organisational levels, indicators that match the objectives and strategy of the business. This is commonly done by starting from the business goal and working in a bottom-up manner $[19,20]$. Hundreds of indicators can be spread throughout the various organisational units on the operational level, but the top management level may have only a few indicators, depending on the structure of the organisation, e.g. number of senior managers and organisational flatness. Figure 1 shows a three-level organisation for the case of a railway, from technical to contractual aspects through regulatory issues.

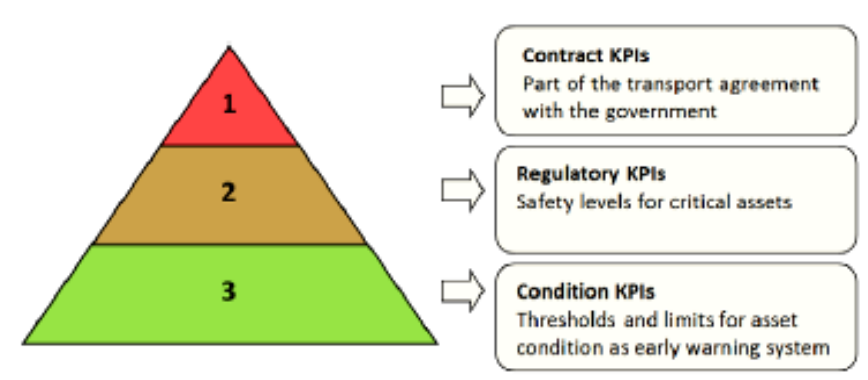

Fig. 1 KPI levels

The output of the development of a MPM-system is a framework, or scorecard, where indicators are grouped into categories, such as the following: technical, functional, strategic level or top management, tactical or middle management functional or supervisors and operators, BSC perspectives (customer, processes, financial and innovation), business areas, key result areas, quality, productivity, health, safety, environment, risk management, quantitative, qualitative, equipment performance, process performance, cost performance, etc.

Campbell [11] classifies performance indicators into three categories: equipment, process and cost performance. Indicators of equipment performance are availability, reliability and OEE; indicators of process performance include the ratio of planned work and schedule compliance; cost performance indicators include maintenance labour and material cost.

Another way of grouping is into leading and lagging indicators which measure future events and events that already have occurred, respectively. Leading indicators are also called operational indicators, monitoring the inputs to a process, and lagging indicators are called financial measures, monitoring the outputs $[12,13]$.

At the end of the day, the selection of the scorecard must be done based on the requirements of appropriate indicators for each level and their optimum aggregation up through the organisation. That is, the scorecard must fulfil the organisational requirements and the interaction between asset management and company profitability.

When it comes to select the indicators it should be taken into account that sometimes there is a delay between policy change and the time the measurements are taken. A second delay occurs between the time the measurement is taken and the appearance of clear results associated with the policy change. These problems must be treated individually against each objective, taking into account that technical levels can expect faster changes in their indicators than corporate levels; at these levels, the KPIs are measures of strategy and it can take longer to get visible results. Once a measure has been identified for a goal and level and is implemented, the method and frequency of data collection have to be specifically tailored to the factors involved: physical parameters, human factors, financial, organisational etc.

\section{MAPPING RAILWAY INFRASTRUCTURE INDICATORS}

Because the indicators used to manage railway infrastructure are comprehensive, a scorecard in which they are split into two large groups with a number of sub-groups is proposed in this work. The two larger groups are managerial and infrastructure condition indicators, as shown in Figure 2 . 


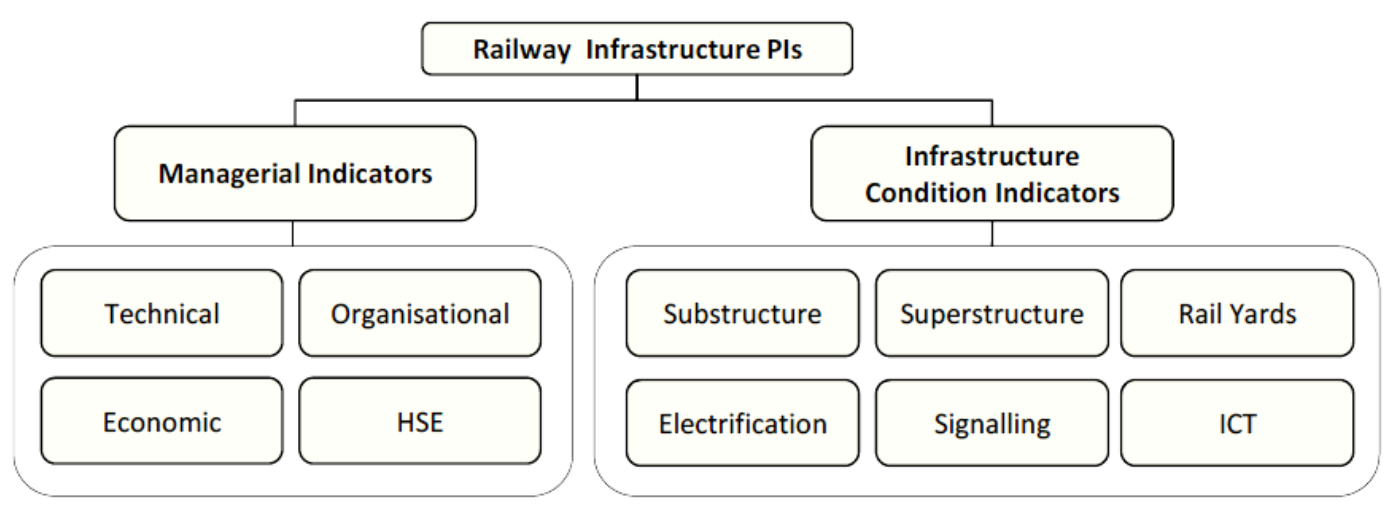

Fig. 2 Structure of railway infrastructure KPIs. ICT stands for information and communication technologies, and HSE stands for health, safety and environment

The former are extracted from various computer systems, e.g. enterprise resource planning (ERP), computerised maintenance management software (CMMS), etc., excluding condition monitoring (CM) data. Therefore, the latter group includes all indicators extracted by sensors and various inspection methods in the railway network. Managerial indicators are at a higher level in the organisational hierarchy than the infrastructure CM indicators; these are closer to the operational level [21].

Increased interoperability and the building of a transEuropean railway network require harmonisation and the standardisation of management across countries. This has led to the increased use of European standards. Consequently, the managerial KPIs identified here follow European standard EN 15341, i.e. economic, technical and organisational KPIs. In the standard, the health, safety and environmental KPIs are in the technical group, but these indicators are considered to have such importance for railways that they have been put into a separate group. The managerial indicators consist, therefore, of four groups, or key result areas (KRAs), as it can be seen in Figure 2.

CM indicators are grouped according to the common engineering sub-systems of railways: substructure, superstructure, rail yards, and electrification, signalling and information communication technologies (ICT). In this, we are following the grouping used by Swedish railway company Trafikverket.

\section{DATA MANAGEMENT}

For a linear asset such as a railway, much information needs to be captured and analysed to assess the overall condition, maintenance, capital spending, and inspection of the railroad tracks.

Examples of information that can be collected include track availability, use of track time, track condition, performance history, and the work performed. Measurements of the condition of the track typically include continuous and spot measurements from automatic inspection vehicles, visual inspections from daily walking inspections, and records of in-services failures. Examples of conditions measured by automatic inspection vehicles include geometry car measurements (deviation from design curves, geometry exceptions to railroad standards, vehicle ride quality exceptions), rail measurements, gage restraint measurements, track deflection and stiffness measurements, clearance measurements, and substructure measurements.

Information on a linear asset is usually collected and maintained, for example, in a set of track charts or line books, as shown in Figure 3.

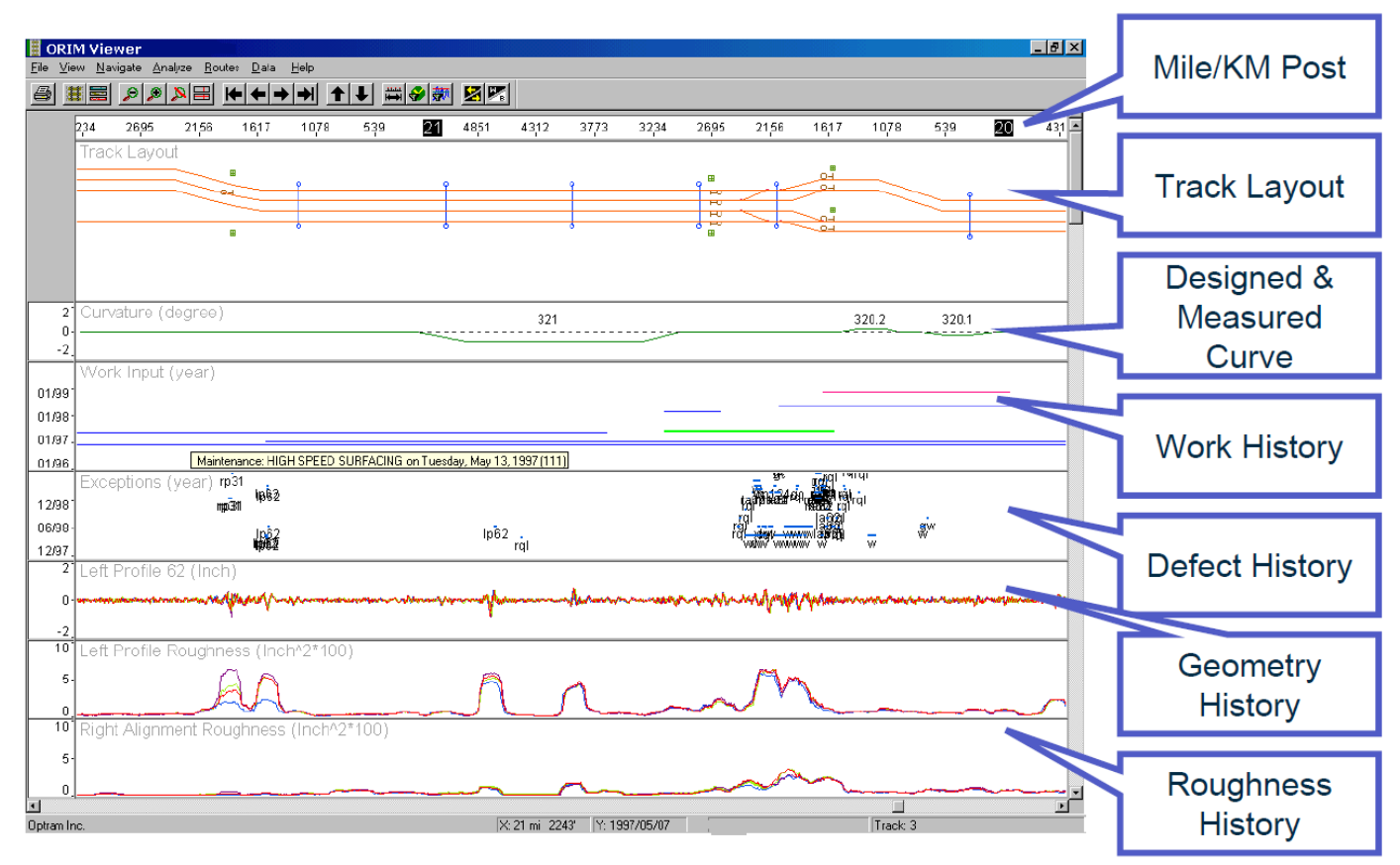

Fig. 2 Physical parameters monitored in linear assets by OPTRAM software 
A track chart is the linear representation of all infrastructure assets along a linear asset based on a maker post and offset measurement system. Updating the track charts generally occurs on an ad hoc basis, so discrepancies, missing facilities, and incorrect location information are common. Even with an accurate map of the corridor, rail, ties, and other corridor assets do not have any physical characteristics that lead to easy identification. Furthermore, problem areas for targeted maintenance often do not obey discrete physical boundaries such as beginning and end of a rail section.

The development of a variety of track condition indicators such as geometry cars, rail defect detection equipment and gage restraint management systems has resulted in a significant amount of new and useful information for track maintenance [14]. However, a large amount of information provided over a large area quickly leads to information overload.

Accordingly, there is a need to create MPM indicators to analyse data on linear assets. Having a unified perspective on the relevant data within a single, accurate format would facilitate the analysis of these data. Accurate MPM indicators would help decision makers determine what should be worked on and why. Such indicators would support the user by providing knowledge of the infrastructure's condition and configuration, so maintenance resources could be targeted to only those areas needing work. The indicators would also help in the planning of such things as facility upgrades and expansions.

\section{FUSION OF CONDITION INDICATORS AND HISTORICAL DA- TA: A NECESSARY INGREDIENT OF INFORMATION AGGRE- GATION}

Indicators must be mapped and grouped if an organisation is to make the right decisions at the right time for the right assets. However, data sources for the railway are so different and information is so disparate that decisions are not easy.

Thus, the information sources comprise two types of data: historical data contained in computerised maintenance management software or CMMS and condition data coming from the $\mathrm{CM}$ systems. CMMS data include information on preventive maintenance (PM) scheduling, automatic work order generation, maintenance inventory control, and data integrity. The $\mathrm{CM}$ systems feature multiplemethod condition monitoring, trend tracking, and expert system diagnoses. These data must be integrated to contextualise decisions and produce aggregated indicators meaningful for the various actors who are managing railway assets and other linear assets. New methods must be developed to merge condition indicators with historical operation and maintenance data to form a solid base for the accurate assessment of the asset's current and future health [15].

The first step in integrating CMMS and CM is devising a way for the two systems to communicate using a common base of information. For example, all equipment monitored by the $\mathrm{CM}$ system must also exist in the CMMS database, and must be called by the same name in each. Next, there must be a system of data cross-referencing between the sensors, meter tags, or other measurement tools in a CM system and the appropriate module in the CMMS that associates readings in one system with readings in the other. Meter readings or alarm triggers that are out of the acceptable CMMS range should trigger a pre-defined work order. Any discrepancy in this cross-referencing for a piece of equipment will nullify the link for that piece of equipment, making the ability to predict problems much less comprehensive. In short, upfront planning of data entry rules and the database setup comprise a critical part of the pre-integration process. The third step in fully integrating a CMMS and CM package is to provide a direct link between the systems' data tables, usually called an "active exchange" of data. The best CMMS databases feature open architecture, such as SQL, Oracle and others. They can be read from and written to by CM programs with certain capabilities.

As it has already been stated, the most obvious obstacle in the integration of CMMS and CM data is the disparate nature of the data types; attempts to remedy this problem have encountered inconsistent implementation and limited scalability. For example, one possibility is to assign the mostly qualitative CMMS data with quantitative indexing, allowing $\mathrm{CM}$ data to be separated into discreet maintenance states. But it is the responsibility of the maintainer to correctly insert the appropriate fault or work code into the maintenance logs, and to date, this has not been done with sufficient accuracy or consistency to be deemed reliable.

Assessing the condition of linear assets requires communication systems that are reliable, flexible and, in most cases, wireless. These systems must also meet the energy constraints defined by the energy management system. The data, once communicated from the sensor systems, will be merged with historical data to assess the current health before being used for prognosis of the future health, as shown in Figure 4.

This is, however, not as simple as it may seem, since the condition monitoring data and the historical data are from completely different time frames. For example, control system data are real-time data measured in terms of seconds, whereas maintenance cycle data are generally measured in terms of calendar based maintenance (e.g., days, weeks, months, quarters, semi-annual, annual), and financial cycle data are measured in terms of fiscal periods. While using a good version of either technology can allow an organisation to meet its maintenance goals, combining the two into one seamless system can have exponentially more positive effects on the maintenance group's performance than either system alone might achieve. Ideally, combining the strengths of a top-notch CMMS with a leading-edge CM will allow the automatic generation of work orders based on information provided by CM's diagnostic and prognostic capabilities.

CMMS and CM systems are both indispensable to maintenance operation improvements [16]. But while CMMS is a great organisational tool, it cannot directly monitor equipment conditions. Meanwhile, a CM system excels at monitoring those equipment conditions, but is not suited to organising the overall maintenance operation. The logical conclusion is to combine the two technologies into a seamless system that provides aggregated indicators about the asset's condition for the different hierarchies in the organisation and avoids catastrophic breakdowns, but eliminates needless repairs to equipment that is running satisfactorily.

\section{DECISION MAKING BASED ON DATA FUSION}

Implementing condition-based maintenance requires the setting of an information system to meet the basic requirements of different audiences. 


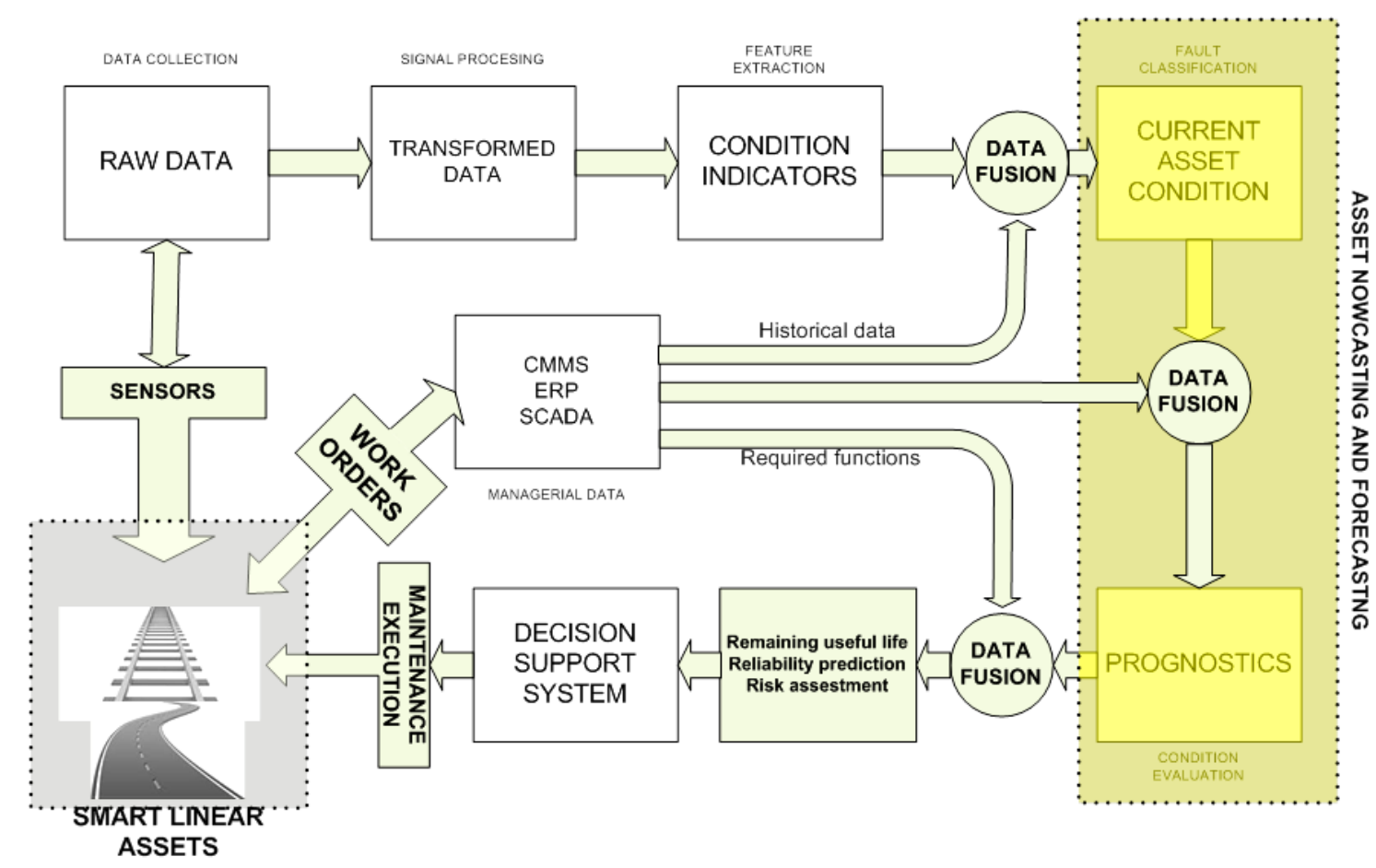

Fig. 4 Architecture for the asset condition assessment

Some examples are the collection and processing of a large quantity of information not previously available on the condition of each part of an asset or the initiation of corrective maintenance actions within the lead-time (the period between the off-limits condition and an emergency shutdown). In this last example two different situations can arise:

1. The condition of the machine is not yet close to breakdown; in this case, the normal procedure of the maintenance planning section is followed.

2. The condition of the asset is already well within the lead -time (near to breakdown); the information must be directly passed on to the maintenance supervision to carry out emergency corrective maintenance actions.

To operate a condition based maintenance program correctly, the maintenance personnel should add information to the system, such as the condition of the asset, the part of the asset probably defective, the probable defect and the time during which failure must be repaired, among others. By scrutinising and correlating the diagnosis against actual findings during repair work, it will be possible to control the examiner training, to improve the correlation between parameters chosen for condition measurement and actual defects found, and to obtain severity curves specific to each machine.

Turning the potential of condition monitoring into a reality requires large amounts of data to be collected, monitored, filtered and turned into actionable information. The cheaper and more ubiquitous the computerised monitoring hardware becomes, the greater the volume of data and the more challenging it becomes to manage and interpret. The vast amount of diagnostic data produced by today's smart field devices can be a very important source for accurate documentation of maintenance activities. But the sheer volume and complexity of such information can be daunting and difficult for maintenance personnel to manage. What is needed is an effective way to compile and organise the data for day-to-day use, while preserving and recording significant events for future reference data.

While this is starting to occur, in many cases the data cannot be used. This can occur because the project managers do not have sufficient time to analyse the computerised data so they do not care about proper storage, due to the fact that the complexity of the data analysis process is beyond the capabilities of the relatively simple maintenance systems commonly used, or because there is no welldefined automated mechanism to extract, pre-process and analyse the data and summarise the results, among other reasons [17].

Maintenance personnel cope with large amounts of field-generated data, turning that information to their advantage in a number of ways, depending on their level in the organisational hierarchy. For example, real time condition monitoring (RTCM) systems produce warnings, alarms and reports that can be used by maintenance people for many purposes. Such systems allow the most important issues to be identified and handled quickly.

The goal is to integrate these types of data with CMMS to generate work orders as needed. The process will be fully automated, linking the time a field device begins to show signs of reduced performance to printing a work order in the maintenance department and dispatching a technician to the scene. Figure 5 shows this automation of work order dispatching. 


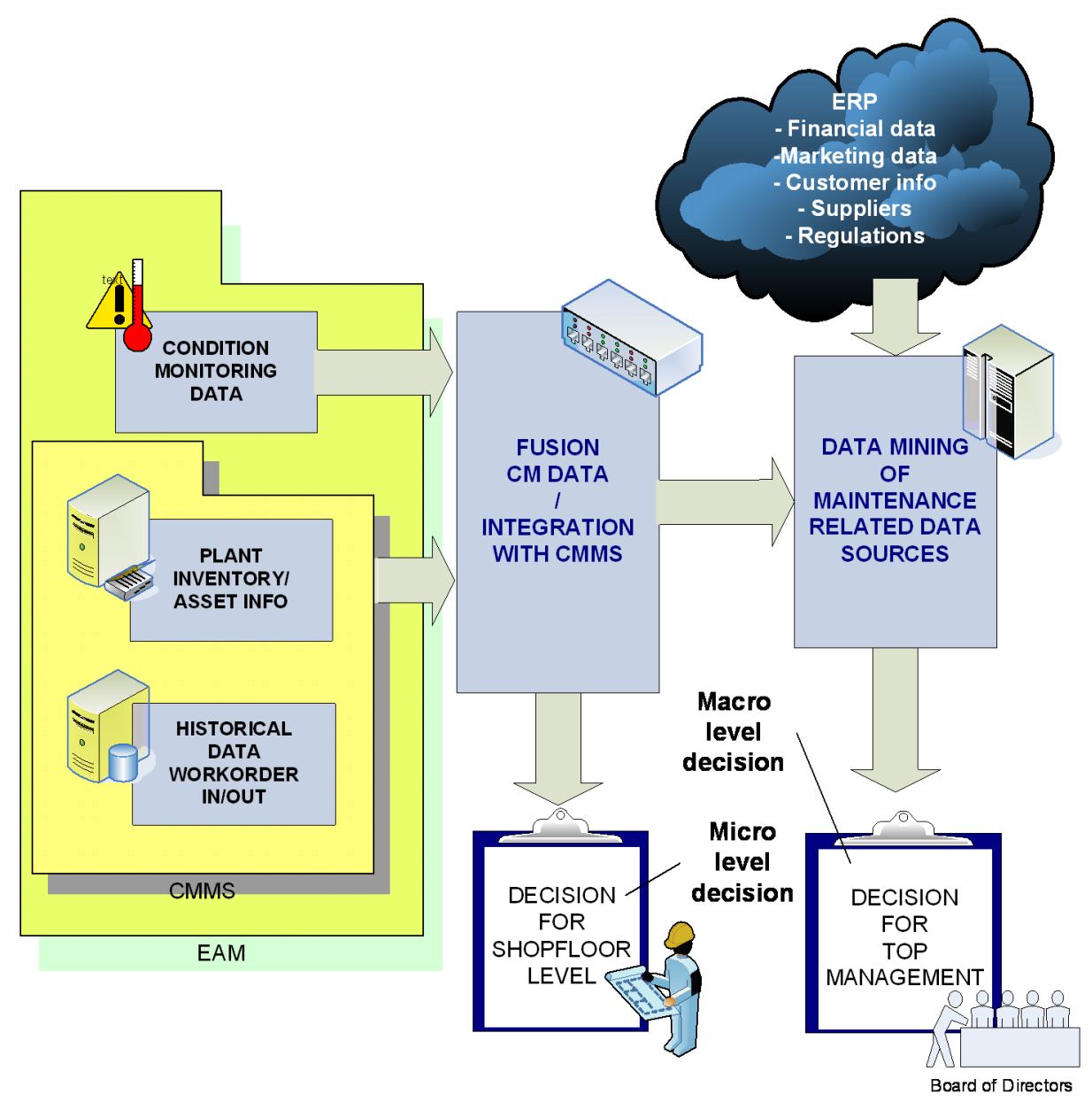

Fig. 5 Two step integration of RTCM and CMMS databases, where EAM means enterprise asset management

This level of integration of CMMS and CM is feasible, given the evolution of IT. With the development of open communication protocols, the information accumulated by smart field devices can be captured by asset management software. It is no longer necessary for technicians to carry handheld communicators or laptops into the plant to evaluate the condition of instruments, some of which are quite inaccessible or in hazardous areas, to be followed by manually documentation of test results and current device status.

Current applications compile databases of every smart instrument used for process control, including its design parameters, original configuration, maintenance history and present operating condition. With these online tools, technicians can obtain up-to-date information on any device; do not have to make manual entries into a system. Every event is recognised and recorded, whether initiated by a technician or caused by an external force such as an equipment breakdown or power failure. This process produces an immediate result for the shop floor level: work orders can be opened and closed by devices that collect information automatically and send a warning if something goes wrong. Users can refer to recorded alerts to identify devices that have been problematic over time and to discover what corrective steps have been taken. Automated documentation provides a seamless record of events in a given area, including communication failures, device malfunctions and process variables that are out of range. Armed with this information, maintenance personnel are better equipped to understand and resolve nagging repeti- tive issues to improve the overall process. If there is an issue, or if maintenance personnel are experiencing a rash of issues, they can go back into the records and get a sense of what has been happening over time. They can search by a specific device or by location.

Since all records are date and time stamped, users can easily determine when and by whom a particular device was changed or tested, including "as found/as left" notations. With this information stored in a database, it should never be necessary for technicians to spend time searching for historical information on a device. Since events can also be recorded manually, users can document unusual occurrences affecting the entire plant, such as a lightning strike or power outage, or individual events like device inspections.

The integration of information has two steps. The first is the integration of technology; here, standards like MIMOSA are working to develop a common hardware and software platform for data storage. In this step asset condition indicators are obtained with the aim of deciding the need to carry out immediate interventions at the shop floor level. Thus, a planning related to the short term can be done. The second step is related to the knowledge extraction required by the integration performed in the first step. In this case, data mining promised to be an effective tool.

Data mining has become useful over the past decade in maintenance to gain more information, to have a better understanding of the behaviour of running assets, and to find optimal maintenance policies derived from the new knowledge. Today, data mining is no longer thought of as a 
set of stand-alone techniques, far from the maintenance applications. Enterprises increasingly require the integration of data mining technology with relational CMMS and $\mathrm{CM}$ databases and their business-oriented applications. To support this move, data mining products are shifting from stand-alone technologies to integration in the relational databases.

A vast amount of available information can only produce new knowledge if it is properly exploited using the right tools. Modern CMMS information is stored in very large relational, or tabular, databases. This format is appropriate for integration, as there are many software tools available to query and investigate the tables. For historical analysis, only certain fields are required, thus allowing the previously mentioned sensitive data to be removed or filtered. The data subset still contains a full history of component faults and related actions, providing a comprehensive maintenance history profile while alleviating security concerns.

Importing CM data into this relational database is somewhat more challenging but possible, since each type of sensor generates different data classes, sampling rates, and number of compiled indicators. Furthermore, each manufacturer stores the collected information in unique proprietary formats, requiring platform-specific importation software to be written. However, most $\mathrm{CM}$ software allows the $\mathrm{CM}$ data to be exported from the original interface so they can be expanded and generalised.

Even when CMMS and CM data co-exist in a single database where they can be queried and explored, automating the discovery of linked events requires additional processing. Relating a given maintenance fault or action, which is textual, to sensor data, which is some arbitrary data class type, can only be accomplished through the compilation of overlapping metadata [18]. The generated fields characterise the location and significance of events, creating a quantified set of parameters by which the disparate data can be compared. Metadata for $\mathrm{CM}$ records are generated differently depending on the data class involved. Onedimensional and dimensionless quantities can be assigned rarity parameters through statistical distribution analysis; higher dimensional data requires using neural networks to identify anomalies. Determining rarity is often accomplished through simple single variable statistical analysis, while severity is typically derived from developers' recommended threshold values. More complex domain types require more advanced, though typically well-understood analyses, such as neural networks which can isolate anomalous points from multidimensional data. It is predicted that through the integration process, more advanced metrics and indicators can be discovered to implement previously unexplored relationships in the data, such as multiparameter trending. This new knowledge can help maintenance personnel determine the remaining useful life of the system, allowing them to schedule operating and maintenance processes based on this information. This information affects replacement of assets, shutdown of the plant, overhauls etc., so it constitutes the second decision level displayed in Figure 5, i.e., strongly related to business goals but useless for immediate interventions.

With the development of an easy-to-use interface and a tight integration with the existing environment, new and interesting patterns will emerge in the data; the derived knowledge will be invaluable in making maintenance decisions.

\section{CONCLUSIONS}

There is a real need for maintenance performance measurement in all sectors, but this need is particularly salient in transportation. In this sector, maintenance is critical, as it affects not just the bottom line financially but also safety. Many KPIs have been developed to measure the quality of the maintenance in various railway assets, including rolling stock and all parts of the infrastructure. Several techniques of grouping indicators have also been developed. However, there is a real need to create composite indicators, aggregating information from bottom to top to serve all actors in maintenance decision making.

The maintenance function affects two different hierarchical levels. On the one hand, information collected in the field coming from sensors is used for condition monitoring purposes and fused for asset condition indicators that mostly serve the purpose of immediate interventions at the shop floor level, i.e. short term planning.

On the other hand, the information from the shop floor level may be fused with historical information and scaled it up to higher levels in the organisation for decisions related to long term planning, including overhauls or asset replacements. The information used in the lower levels may be merged and fused with managerial information to produce indicators adapted to the different levels of the organisation, facilitating the decision making process by avoiding the common mistake of having many indicators used in all levels without segregating them by user.

The methodology proposed here is consistent with the ISO 55000's establishment of mechanisms for continuous maintenance improvement; it also reflects the fact that huge amounts of data are collected on a daily basis and must be filtered to provide the right information to the right users.

\section{ACNOWLEDGMENTS}

This research has been partially supported by OPTIRAIL, a project funded by the $7^{\text {th }}$ Framework Programme of the European Commission. This project has received funding from the European Union's Seventh Programme for research, technological development and demonstration under grant agreement No 314031.

\section{REFERENCES}

[1] U. Kumar, D. Galar, A. Parida, C. Stenstron and L. Berges, "Maintenance performance metrics: a state of the art review", Journal of Quality in Maintenance Engineering, vol. 19, no. 3, pp. 233-277, 2013.

[2] UNE-EN 15341:2008 Mantenimiento. Indicadores clave de rendimiento del mantenimiento, UNE AENOR, 2008.

[3] V. Boisevert, N. Holec et al., "Economic and Environmental Information for Sustainability. Valuation for sustainable development: methods and policy indicators", in Valuation for Sustainable Development: Methods and Policy Indicators, S. Faucheux and M. O'Connor, Eds. Cheltenham: Edward Elgar Publishing, 1998, pp. 99-119.

[4] T.J. Wilmering, A.V. Ramesh, Mar. "Assessing the Impact of Health Management Approaches on System Total Cost of Ownership", in IEEE Aerospace Conference, Big Sky, MT, USA, 2005, pp. 1-11.

[5] A. Parida and U. Kumar, "Maintenance Productivity and Performance Measurement", in Handbook of Maintenance Management and Engineering, part I, M. 
Ben-Daya, S.O. Duffuaa, A. Raouf, J. Knezevic and D. Ait-Kadi, Eds., 2009, pp. 17-41.

[6] A. Parida and G. Chattopadhyay, "Development of a multi-criteria hierarchical framework for maintenance performance measurement (MPM)", Journal of Quality in Maintenance Engineering, vol. 13, no. 3, pp. 241258, 2007.

[7] A. Parida and U. Kumar, "Maintenance performance measurement (MPM): issues and challenges", Journal of Quality in Maintenance Engineering, vol. 12, no. 3, pp. 239-225, 2006.

[8] T. Wireman, Developing performance indicators for managing maintenance. New York: Industrial Press, 1998.

[9] D. Mata, J.M. Aller and A. Bueno, "Análisis Probabilístico del Mantenimiento Predictivo y Correctivo de Máquinas Eléctricas Rotativas en una Planta Siderúrgica", Universidad, Ciencia y Tecnología, vol. 12, no. 49, 2008.

[10] J. Woodhouse. (2004). Asset Management - An Introduction. Institute of Asset Management [Online].

Available: http://www.iamuk.org/ iam publications.htm

[11] J.D. Campbell, Uptime: Strategies for Excellence in Maintenance Management, 1st ed., Portland: Productivity Press, 1995.

[12] R.S. Kaplan and D.P. Norton, "The Balanced Scorecard - Measures that Drive Performance", Harvard Business Review, vol. 70, no. 1, pp. 71-79, 1992.

[13] R.S. Kaplan and D.P. Norton, The Balanced Scorecard: Translating Strategy into Action, 1st ed, Boston: Harvard Business Press, 1996.
[14] A. Parida, "Managing Information is the key to Maintenance Effectiveness", in e-Proc. of Intelligent Maintenance System, Arles, France, 2004, pp. 15-17.

[15] D. Galar et al., "Maintenance decision making based on different types of data fusion", Eksploatacja $i$ niezawodność - Maintenance and Reliability, vol. 14, no. 2, pp. 135-144, 2012.

[16] D. Galar et al., "Integration of disparate data sources to perform maintenance prognosis and optimal decision making", Insight: Non-Destructive Testing and Condition Monitoring, vol. 54, no. 8, pp. 440-445, 2012.

[17] L. Soibelman and H. Kim, "Data preparation process for construction knowledge generation through knowledge discovery in databases", Journal of Computing in Civil Engineering, vol. 16, no. 1, pp. 39-48, 2002.

[18] W. Tianhao, F.M. Khan, T.A. Fisher, L.A. Shuler and W.M. Pottenger, "Posting Act Tagging Using Transformation-Based Learning", in Proc. of the Workshop on Foundations of Data Mining and Discovery, 1992.

[19] C. Stenström, A. Parida, J. Lundberg and U. Kumar, "Development of an integrity index for benchmarking and monitoring rail infrastructure: application of composite indicators", International Journal of Rail Transportation, vol. 3, no. 2, pp. 61-80, 2015.

[20] C. Stenström and A. Parida, Link and Effect Model for Maintenance of Railway Infrastructure, Research report, Luleå University of Technology, Luleå, 2013.

[21] C. Stenström, "Maintenance performance measurement of railway infrastructure with focus on the Swedish network", Technical report, Luleå University of Technology, Luleå, 2012.

\footnotetext{
Roberto Villarejo ${ }^{1}$, Carl-Anders Johansson ${ }^{1}$, Urko Leturiondo ${ }^{1,2}$, PhD.

Victor Simon ${ }^{1}$, MSc, Dammika Seneviratne ${ }^{1}$, PhD., prof. Diego Galar ${ }^{1}$

${ }^{1}$ Luleå University of Technology

97187 Luleå, SWEDEN

${ }^{2}$ IK4-Ikerlan, Arrasate-Mondragón,

$\mathrm{P}^{\circ}$. J. $\mathrm{M}^{\mathrm{a}}$. Arizmendiarrieta, 220500 Arrasate-Mondragón, SPAIN

e-mail: roberto.villarejo@ltu.se, carl-anders.johansson@ltu.se,

1,2 uleturiondo@ikerlan.es, victor.simon@ltu.se,

dammika.seneviratne@Itu.se,diego.galar@Itu.se
} 